\title{
Experimental Study of Single Expansion Ramp Nozzle Performance Using Pitot Pressure and Static Pressure Measurements
}

\author{
Sergio Nicolas Pachón Laitón ${ }^{D},{ }^{1}$ João Felipe de Araujo Martos $\mathbb{D}^{2},{ }^{2}$ Israel da Silveira Rego, \\ George Santos Marinho, ${ }^{4}$ and Paulo Gilberto de Paula Toro ${ }^{4}$ \\ ${ }^{1}$ Instituto Tecnológico de Aeronáutica (ITA), Praça Marechal Eduardo Gomes, 50 Vila das Acácias, CEP 12.228-900, São José \\ dos Campos, São Paulo, Brazil \\ ${ }^{2}$ European Space Research and Technology Centre (ESTEC)-ESA, Keplerlaan 1, 2201 AZ Noordwijk, Netherlands \\ ${ }^{3}$ Instituto de Estudos Avançados-Trevo Coronel Aviador José Alberto Albano do Amarante, no. 1, CEP 12.228-001, São José \\ dos Campos, SP, Brazil \\ ${ }^{4}$ Universidade Federal do Rio Grande do Norte (UFRN)-Centro de Tecnologia, Av. Senador Salgado Filho, \\ 3000-Campus Universitário, Lagoa Nova CEP 59.078-970, Natal, RN, Brazil
}

Correspondence should be addressed to Sergio Nicolas Pachón Laitón; snpachonl@libertadores.edu.co

Received 3 July 2018; Revised 22 October 2018; Accepted 29 October 2018; Published 27 February 2019

Academic Editor: Gustaaf B. Jacobs

Copyright (c) 2019 Sergio Nicolas Pachón Laitón et al. This is an open access article distributed under the Creative Commons Attribution License, which permits unrestricted use, distribution, and reproduction in any medium, provided the original work is properly cited.

\begin{abstract}
In order to overcome the drag at hypersonic speed, hypersonic flight vehicles require a high level of integration between the airframe and the propulsion system. Propulsion system based on scramjet engine needs a close interaction between its aerodynamics and stability. Hypersonic vehicle nozzles which are responsible for generating most of the thrust generally are fused with the vehicle afterbody influencing the thrust efficiency and vehicle stability. Single expansion ramp nozzles (SERN) produce enough thrust necessary to hypersonic flight and are the subject of analysis of this work. Flow expansion within a nozzle is naturally 3D phenomena; however, the use of side walls controls the expansion approximating it to a $2 \mathrm{D}$ flow confined. An experimental study of nozzle performance traditionally uses the stagnation conditions and the area ratio of the diverging section of the tunnel for approaching the combustor exit conditions. In this work, a complete hypersonic vehicle based on scramjet propulsion is installed in the test section of a hypersonic shock tunnel. Therefore, the SERN inlet conditions are the real conditions from the combustor exit. The performance of a SERN is evaluated experimentally under real conditions obtained from the combustor exit. To quantify the SERN performance parameters such as thrust, axial thrust coefficient $C_{f x}$ and lift $L$ are investigated and evaluated. The generated thrust was determined from both static and pitot pressure measurements considering the installation of side walls to approximate 2D flow. Measurements obtained by a rake show that the flow at the nozzle exit is not symmetric. Pitot and pressure measurements inside the combustion chamber show nonuniform flow condition as expected due to side wall compression and boundary layer. The total axial thrust for the nozzle obtained with the side wall is slightly higher than without it. Static pressure measurements at the centerline of the nozzle show that the residence time of the flow in the expansion section is short enough and the flow of the central region of the nozzle is not altered by the lateral expansion when nozzle configuration does not include side walls.
\end{abstract}

\section{Introduction}

Hypersonic air-breathing propulsion systems based on scramjet engines is one potential alternative to rocket propulsion systems. Rocket propulsion requires additional systems for storage and handling the oxidant for combustion limiting the overall payload. For hypersonic air-breathing propulsion systems, the oxidant is obtained from the 
atmosphere allowing reducing weight and allowing higher payloads.

The Laboratory of Aerothermodynamics and Hypersonics Prof. Henry T. Nagamatsu at the Institute for Advanced Studies (IEAv), Brazil, is investigating and developing a hypersonic vehicle with an airframe-integrated scramjet engine as an option of space access in the near future [1]. The main objective is to design, develop, and manufacture a technological demonstrator 14-X based on waverider concept to obtain lift at higher altitudes and on scramjet technology to generate enough thrust for hypersonic flight through the atmosphere at $30 \mathrm{~km}$ altitude and Mach number 10 .

The $14-\mathrm{X} \mathrm{B}$ is a simplified version of the vehicle $14-\mathrm{X}$ designed to perform the experimental ground test of the scramjet technology in a hypersonic shock tunnel. Previous experimental research of the first version of the 14 -X B vehicle [2-4] has been done and focused on the flow field analysis at the inlet and combustion section to check undesired design issues. These experimental investigations were developed in the hypersonic shock tunnel T3 of IEAv, under the conditions of Mach number 7, pressure, and temperature close to conditions at $30 \mathrm{~km}$ altitude. In these investigations, since the study of the flow field on the inlet and on the combustor was the main objective, however, the nozzle flow field was neglected.

Hypersonic vehicles require a high level of integration between airframe and propulsion systems, those that uses air-breathing propulsion based on scramjet engines have a close interaction with vehicle stability as well [5-8]. Furthermore, inlet and nozzle components generally are fused within vehicle forebody and afterbody, respectively, influencing thrust efficiency and vehicle trimmability [9-11]. For several flight stages of the hypersonic vehicle, the scramjet engine operates in without fuel injection planning with energy generated during the combustion [12]. For these conditions, pressure distribution on nozzle surfaces influences the vehicle control and stability.

Intakes and nozzles have similar characteristics. The intake seeks to minimize the stream thrust loss when the area is decreased while the nozzle aim at maximizing the stream thrust gain when the area increases. Therefore, nozzle performance significantly influences the overall propulsion system efficiency and even the entire hypersonic vehicle operability [13].

Nozzle function is to accelerate the heated air from the combustor to produce thrust in a scramjet engine, transforming the flow internal energy into kinetic energy. The nozzle design is critical to obtain the necessary thrust to accelerate an aerospace vehicle. Generally, hypersonic vehicles powered by scramjet engine use a single expansion ramp nozzles (SERN) producing enough thrust necessary to hypersonic flight. Due to flow nature, this SERN characteristic turns the nozzle flow field analyses to a problem approximately $2 \mathrm{D}$.

SERN is used to minimize the frictional drag and nozzle weight while taking out most of the thrust from the high-pressure flow on the afterbody [6, 14]. Moreover, SERN enhances the internal/external integration level for hypersonic vehicles [9] and has the ability to adapt automatically to variations in environmental static pressure while in the off-design conditions [7]. However, when the operation conditions (pressure, Mach number, angle of attack, and mostly when the engine is started or turned off) vary drastically, changes in lift and pitch moment are inevitably.

Flow expansion within a nozzle is naturally a $3 \mathrm{D}$ phenomenon; however the use of side walls allows to control this expansion approximating it to a $2 \mathrm{D}$ flow $[15,16]$. For the same flow conditions, the air flow confined by the side walls produces a different pressure distribution compared to the pressure distribution of an unconfined flow. For a confined flow, the expansion is developed mainly through two components (downstream direction and height direction), being the third component restricted by the side walls $[16,17]$. Consequently, as expected, the pressure distribution over the nozzle will be greater for the $2 \mathrm{D}$ case. Thus, this pressure difference produces variations in the aerodynamic stability, in the pitch moment and certainly in the generated thrust [16].

Several studies have been conducted investigating theoretically the SERN nozzle performance. The work developed by Mo et al. [10] evaluated the aerodynamic performance for a scramjet nozzle designed by the rotational method of characteristics (MOC) considering a nonuniform inlet flow. In [1820], the SERN performance investigates the relation to geometrical constraints and design variables such as divergent angles, total length, cowl length, and Mach number at nozzle entrance.

Experimental studies of SERN performance available in open literature implement different methodologies to characterize the flow field on the nozzle [21-23]. In these investigations, the pressure-sensitive paint and pressure system incorporation methods are used to determine the static pressure distribution; moreover, pitot-pressure measurement is used to provide the pressure flow field of the nozzle.

Traditionally experimental studies of nozzle performance are performed over individual models exclusive for the expansion section $[24,25]$. Therefore the flow field conditions at nozzle entrance are determined by the tunnel freestream flow conditions and the tunnel stagnation flow conditions, with the purpose of approaching the combustor exit conditions. In this framework, a complete hypersonic air-breathing vehicle is installed in the test section of the hypersonic shock tunnel and the nozzle inlet conditions are supplied directly from the combustor exit.

The main goal of the present work is to evaluate experimentally the performance of a single expansion ramp nozzle of the new version of the $14-\mathrm{X} B$ model at flight conditions (30 km altitude and Mach number 7). The thrust generated by the SERN was determined from both static and pitot pressure measurements comparing the use of side walls to approximate $2 \mathrm{D}$ flow. The results from side walls and without side walls were compared, and the effects of these configurations on the thrust, thrust coefficient, and lift were evaluated.

\section{Experimental Setup}

2.1. Hypersonic Vehicle and Nozzle Model. Experiments with a full scale hypersonic vehicle with a scramjet propulsion system were carried out. The model is a technological demonstrator of a hypersonic air-breathing propulsion 


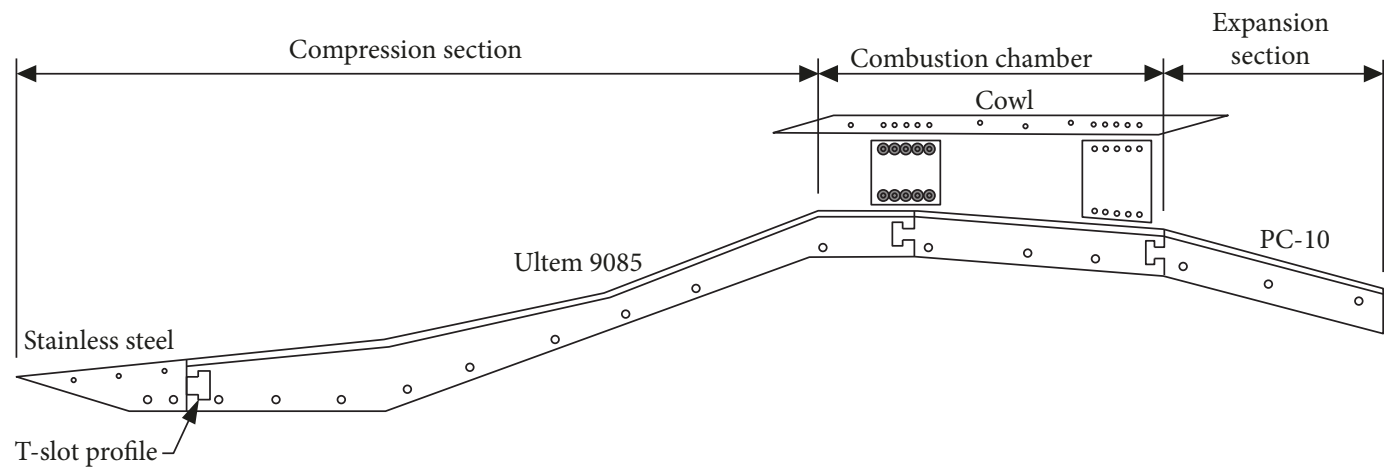

FIgURE 1: Assembly and materials of the experimental model.

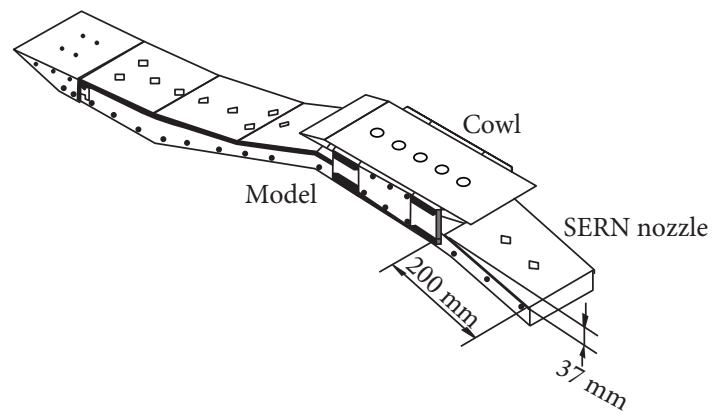

(a)

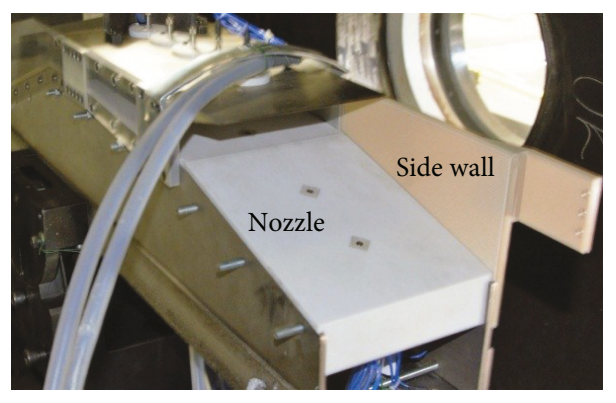

(b)

Figure 2: Experimental nozzle model. (a) Geometry of the SERN nozzle. (b) Printed side walls installed at the nozzle.

system, based on a supersonic combustion ramjet (scramjet) designed to operate at $30 \mathrm{~km}$ of altitude and speed flight of Mach number 7. The scramjet engine is integrated with the geometry of the hypersonic vehicle. The scramjet engine consists mainly of a compression section, a combustion section, and an expansion section. Three ramps at the compression section perform the flow field compression entering the engine, whereas the combustion chamber section is a constant area duct that incorporates an expansion angle at the end to fit the increase of the boundary layer due to high pressure in the process of combustion (see Figure 1). The afterbody of the vehicle is a $2 \mathrm{D}$ single expansion ramp nozzle model.

The model construction combines classical metal machining and $3 \mathrm{D}$ printing techniques. The model was modularly divided to assure its integrity in the event of an unforeseen event. The modules are assembled by insertion through $\mathrm{T}$-slot profiles providing a continuous surface minimizing the influence connection gaps on the flow field. The experimental model was divided into pieces similar to the main components of the scramjet engines (see Figure 1). The compression section is a triple wedge printed in a single piece to avoid disturbance on the boundary layer caused by links between pieces, whereas the combustor chamber (injector) and the external expansion were printed as individual pieces to make changes easier.

Model sections were numerically analyzed to determine the expected flow properties along the model and consequently the expected loads for printed composite material.
Since the triple wedge and isolator are subjected to the higher dynamic pressure, it was printed on a ULTEM 9085 material (Figure 1), which features a high strengthto-weight ratio, high thermal and chemical resistance, and $100 \mathrm{MPa}$ of compressive strength. The thermoplastic material ULTEM 9085 is available on the Stratasys Fortus 900 $3 \mathrm{D}$ printer but is costly. For this experimental investigation, combustion will not be considered; therefore, the combustor and nozzle parts were printed of polycarbonate (PC10) material which offers accuracy, durability, and stability with $69 \mathrm{MPa}$ of compressive strength (Figure 1); the PC10 is economical compared to ULTEM 9085. The leading edge (Figure 1) and cowl regions are machined using stainless steel 316 as they bear overstrain by impact pressure and incident shock waves, respectively.

As stated before, the nozzle consists of a 2D single expansion ramp nozzle (SERN) which is a flat ramp surface located after the combustor exit station with a total length of $200 \mathrm{~mm}$ and a total height of $37 \mathrm{~mm}$ (Figure 2(a)). Its surface has an asymmetric configuration; the upper region interacts with the hypersonic airflow around the vehicle. To produce a quasi-one-dimensional flow, printed side walls are attached to the model (Figure 2(b)).

2.2. Hypersonic Shock Tunnel and Test Conditions. The experiments were carried out in the T3 hypersonic shock tunnel of the Laboratory of Aerothermodynamics and Hypersonics Prof. Henry T. Nagamatsu. This facility is a reflected hypersonic shock tunnel equipped with a 


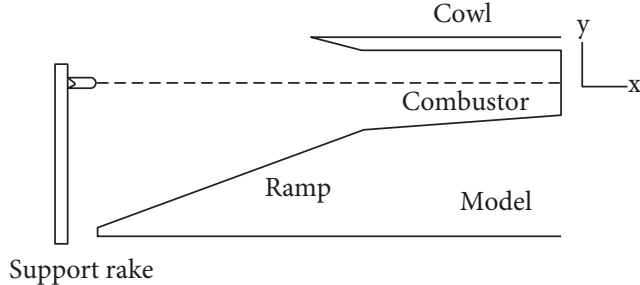

(a)

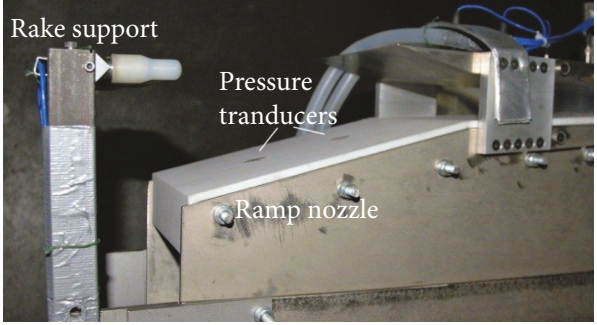

(b)

FIGURe 3: Pitot rake installation at the nozzle exit. (a) Sketch of the pitot rake position. (b) Pitot rake installation.

convergent-divergent nozzle with different throat diameters to vary the Mach number and enthalpy in the test section. The T3 hypersonic shock tunnel was designed to be operated in the 6-25 flight Mach number range [26]. This facility enables reservoir enthalpies in the excess of $10 \mathrm{MJ} / \mathrm{kg}$ and reservoir pressures up to $25 \mathrm{MPa}$, with estimated useful test time up to $10 \mathrm{~ms}$, when operated in the equilibrium interface mode. For these experiments, helium was used as gas on a high-pressure reservoir (driver) and the tunnel was operated on the tailor condition to produce a useful test time of roughly $2 \mathrm{~ms}$. The reservoir conditions of the shock tunnel, total pressure $\left(p_{t}\right)$, and total temperature $\left(T_{t}\right)$, for these experiments with Mach 7 nozzle, are $p_{t}=10.7 \mathrm{MPa}$ $\left(\Delta p_{t} / p_{t}=3.0 \%\right)$ and $T_{t}=2246 \mathrm{~K}\left(\Delta T_{t} / T_{t}=1.6 \%\right)$, respectively. Quartz windows are installed in the opposite walls of the test section to provide visual access for Schlieren visualization technique.

2.3. Rake and Sensors. A pitot rake was used to obtain the pitot pressure distributions at the nozzle exit. This rake consists of 7 horizontal pitot pressure tubes placed $25 \mathrm{~mm}$ apart, covering a total pitot rake span of $150 \mathrm{~mm}$ which is the same nozzle span. The transverse line of the pitot sensors was aligned with the vertical center of the combustor (Figure 3(a)). The nozzle ramp is equipped with 2 PCB piezoelectric pressure transducer model 112A22 installed in flush mode along the center line. These transducers allow the measurement of the static pressure at two points of the nozzle ramp which are used to determinate the thrust of the nozzle. Figure 3(b) shows a lateral view of the nozzle and the pitot rake installed in the hypersonic shock tunnel test section.

\section{Flow Characterization}

3.1. Nozzle Entrance Conditions. For the experimental tests, the static pressure distribution was obtained by pressure measurements of PCB transducers at discrete points, while parameters such as total pressure and Mach number are not obtained during the experiment. Hence, the flow conditions at the SERN entrance must be calculated indirectly from the experimental data.

The flow field conditions at the nozzle entrance are determined by pressure measurements and a theoretical analysis. The theoretical analysis computes the Mach number, temperature, static, and total pressure for 1D compressible flow of the scramjet engine [27]. This method combines the oblique shock wave relations, flow with friction, and expansion wave theory for hypersonic flow. Also, the method considering the flow total pressure losses through the scramjet engine applying continuity momentum and energy equation for a thermally perfect gas with variation of the specific heat ratio. The equations and model geometry are set up in an algorithm, and the free stream experimental conditions are used as input data. The algorithm also incorporates a methodology to consider the boundary layer and the loss of total pressure by oblique shock waves and by friction.

The commercial software ANSYS Fluent version 18.2 was employed to numerically analyze the pressure distribution over the experimental model to compare it with the theoretical results. ANSYS Fluent solves simultaneously all the integral governing equations (continuity, momentum, and energy). The ANSYS Fluent disposes two numerical methods: pressure-based solver and density-based solver. The pressure-based approach was developed to be used for low-speed incompressible flows, while the density-based approach is used for high-speed compressible flows. In the density-based method, the velocity and density fields are obtained from the continuity and momentum equations, and the pressure field is obtained from the equation of state.

The boundary wall conditions considered were the isothermal cold wall $(300 \mathrm{~K})$ due to the short test time available on the hypersonic shock tunnel. In addition, the transitional viscous model used was the Transition SST (fluent code) with ideal gas that according to a previous analysis is the most suitable option for this case considering the results obtained and computational power available [28].

In the computational domain, the model geometry is divided into different regions to apply individualized refinements (Figure 4). The unstructured grid is composed of triangular elements generated using ANSYS Fluent. The grid is densely clustered near the cowl leading edge and inside of the scramjet engine in order to better calculate the physical interactions in the boundary layer and at the regions near the leading edge. Details of the size of the elements of each region are shown in Figure 4. The supersonic air flows from left to right, and the free stream conditions Mach number $\left(M_{\infty}\right)$, the static temperature $\left(T_{\infty}\right)$, and the static pressure $\left(p_{\infty}\right)$ used for the simulation are $7,241 \mathrm{~K}$, and $1772 \mathrm{~Pa}$, respectively.

In order to validate the theoretical method, its results of pressure distribution are compared with numerical results and with the static pressure distribution measured experimentally. Figure 5 shows a comparison for the pressure distributions along the model surfaces considering each methodology. 


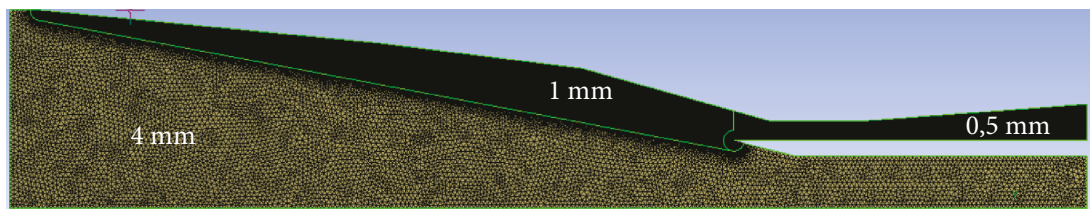

Figure 4: Coarse view of the computational domain of the hypersonic vehicle and details of the size of the elements.

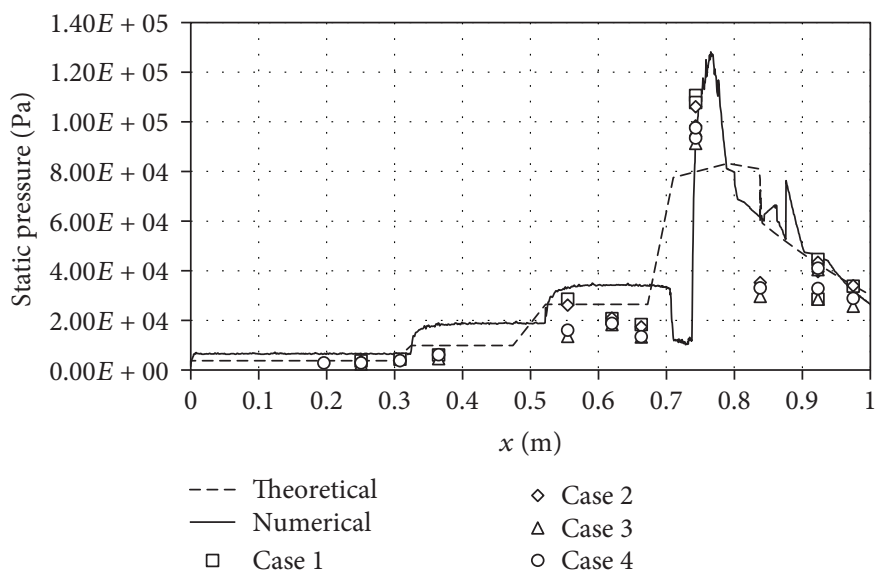

FiguRE 5: Static pressure distribution from compression ramps to the combustor exit of the experimental model.

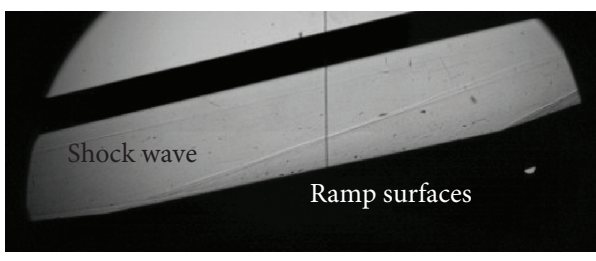

(a)

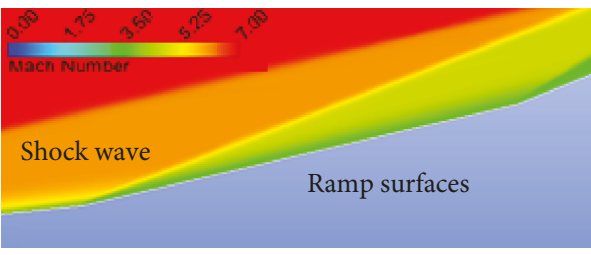

(b)

Figure 6: Oblique shock waves of the compression section. (a) Schlieren photography for the compression section. (b) Mach number contours for the compression section.

Theoretical and numerical results are in good agreement with the experimental data obtained. However, shock wave reflection inside the combustion chamber produces pressure peaks and oscillation of pressure distribution which is showed by the numerical and experimental results. For theoretical results, the oscillation of the pressure distribution in the combustion chamber is not considered since the conditions of shock on-lip and shock on-corner of the inlet are considered. The shock wave reflection effects on the pressure distribution are moderate at the exit of the combustion chamber, when the numerical and experimental results are compared with the theoretical results. This implies that the theoretical model employed can be used with confidence to compute the flow pressure at the exit of the combustor chamber in power off operation (ideal gas).

The experimental Mach number in the compression section is determined using the static pressure measurement from PCB sensors and the shock wave angle obtained through Schlieren photographs. Figure 6(a) shows a Schlieren photograph of the shock waves produced by each surface of the compression section. The shock wave angles are
TABLE 1: Comparison of oblique shock wave angles.

\begin{tabular}{lccc}
\hline Surface & Schlieren [deg] & Numerical [deg] & Theoretical [deg] \\
\hline $1^{\text {st }}$ ramp & $13.0 \pm 0.3$ & $12.5 \pm 0.3$ & 12.4 \\
$2^{\text {nd }}$ ramp & $20.2 \pm 0.4$ & $20.0 \pm 0.4$ & 20.1 \\
$3^{\text {rd }}$ ramp & $29.0 \pm 0.4$ & $29.4 \pm 0.3$ & 30.2 \\
\hline
\end{tabular}

measured directly on the Schlieren image in the relation of the longitudinal axis of the vehicle (Table 1).

Figure 6(b) shows the Mach number contours for the compression section obtained numerically; the shock wave angles are compared with the corresponding Schlieren pictures and as expected they are in agreement (Table 1).

Table 1 compares the oblique shock wave angle values for the first, second, and third ramps obtained from experimental, numerical, and theoretical methodologies. The overall variation discrepancy between results of theoretical and experimental analyses is less than 5\%, implying that the physical model employed for theoretical methodology is accurately simulated. Uncertainties in the shock 


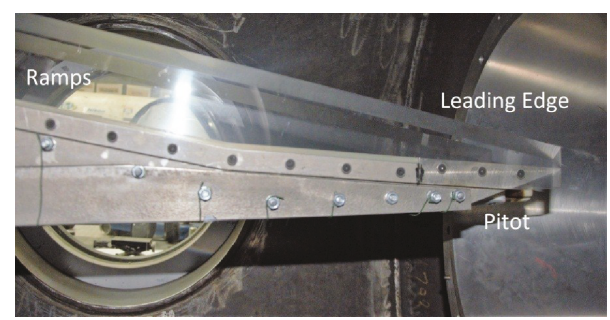

Figure 7: Pitot pressure tubes at the leading edge of the compression ramps.

TABLE 2: Free stream test conditions.

\begin{tabular}{lccc}
\hline Case & $M_{\infty}$ & $p_{\infty}[\mathrm{Pa}]$ & $T_{\infty}[\mathrm{K}]$ \\
\hline 1 & $7.01 \pm 0.02$ & $1770 \pm 41$ & $230 \pm 9$ \\
2 & $7.03 \pm 0.02$ & $1699 \pm 50$ & $228 \pm 8$ \\
3 & $7.20 \pm 0.01$ & $1611 \pm 31$ & $223 \pm 6$ \\
4 & $6.98 \pm 0.01$ & $1701 \pm 44$ & $246 \pm 7$ \\
5 & $6.95 \pm 0.03$ & $2009 \pm 91$ & $255 \pm 11$ \\
6 & $6.96 \pm 0.02$ & $1891 \pm 67$ & $252 \pm 8$ \\
7 & $6.90 \pm 0.01$ & $1923 \pm 59$ & $257 \pm 8$ \\
\hline
\end{tabular}

wave angle measurement result in errors of $6 \%$ in Mach number estimation.

3.2. Free Stream Conditions. The free stream conditions of the test section were determined from pressure measurements through pitot probes located after the tunnel nozzle exit and aligned with the vehicle model inlet as illustrated in Figure 7.

The reservoir pressure $p_{t}$ of the hypersonic shock tunnel is considered constant during the flow expansion in the conical nozzle. The Mach number and the other properties, pressure and temperature, at the test section were calculated by isentropic flow relations. The free stream flow conditions of the tests are summarized in Table 2.

3.3. Nozzle Performance. To quantify the SERN performance parameters such as axial thrust, thrust coefficient $C_{f x}$ and lift $L$ are introduced. The axial thrust $F_{x}$ and lift $L$ are the $x$ and $y$ direction components of the thrust $F$ acting on the nozzle, respectively. The axial thrust coefficient is calculated as follows:

$$
\begin{aligned}
C_{f x} & =\frac{F_{x}}{F_{s}-I_{\mathrm{in}}} \\
I_{\mathrm{in}} & =m V_{\mathrm{in}}+\left(p_{\mathrm{in}}-p_{e}\right) A_{\mathrm{in}}, \\
F_{s} & =\dot{m} \sqrt{\frac{2 \gamma}{\gamma-1} R T_{t}\left[1-\left(\frac{p_{e}}{p_{t}}\right)^{(\gamma-1) / \gamma}\right]},
\end{aligned}
$$

where $I_{\text {in }}$ is the impulse function at the nozzle entrance defined by mass flow rate $\dot{m}$, flow velocity $V_{\text {in }}$, and static pressure $p_{\text {in }}$ at the nozzle entrance, pressure at the nozzle exit $p_{e}$, and area at the nozzle entrance $A_{\text {in }}$. The ideal thrust $F_{s}$ is needed to calculate the thrust efficiency; this parameter is defined as a function of the specific heat ratio $\gamma$, total temperature $T_{t}$, and total pressure $p_{t}$ at the nozzle entrance. The thrust is calculated from the pressure measured by the pitot rake and also of the static pressure transducers.

The axial thrust coefficient of the SERN, which reflects the thrust efficiency, improves the vehicle acceleration. However, lift and pitching moment play an important role in the stability and trimming of the vehicle.

Thrust from pitot measurements is calculated by linear moment analysis in the nozzle. The thrust of a jet propulsion device as a function of the Mach number $(M)$ assuming ideal one-dimensional flow and applying the ideal gas model can be obtained by

$$
F=\left(\gamma M_{e}^{2}+1\right) p_{e} A_{e}
$$

Equation (2) can be used to compute the thrust from an exit plane of static pressure measurements. The thrust varies essentially linearly with $\gamma$ and square of the Mach number. Therefore, small errors would contribute to large errors in the estimated thrust. However, it is possible to use the total pressure measurements after the normal shock wave obtained through pitot probes (pitot pressure) rather than static pressure. In this sense, Equation (2) may be written in the function of the ratio of the static pressure to the pitot pressure as

$$
F=\left(\gamma M_{e}^{2}+1\right) \frac{p_{e}}{P_{\mathrm{pit}}} p_{\mathrm{pit}} A_{e}
$$

where $p_{e} / P_{\text {pit }}$ assuming $\gamma$ constant is given by

$\frac{p_{e}}{p_{\mathrm{pit}}}=\frac{1}{((\gamma+1) / 2) M_{e}^{2}\left[((\gamma+1) / 2) M_{e}^{2} /(2 \gamma /(\gamma+1)) M_{e}^{2}-((\gamma-1) /(\gamma+1))\right]^{1 /(\gamma-1)}}$.

In [23], it is demonstrated that the pitot pressure thrust function is relatively insensitive to both $M_{e}$ and $\gamma$ and, for a sufficiently high Mach number, the function is completely insensitive for the Mach number. This is one of the advantages of using pitot pressure rather than static pressure.

To compute thrust with rake pressure data at points where there are no sensors, it is assumed that the pressure is constant between two pressure transductors in spanwise $\mathrm{dz}$ (see Figure 8). The total thrust of the nozzle is determined by the sum of the thrust of each sensor multiplied with the corresponding height $\left(h_{\text {exit }}\right)$ in the vertical $(y)$ direction, which is the height of the projected exit area of the nozzle as shown in Figure 8. This simplification produces high values of thrust because the pressure distribution of a nozzle is not the same in the vertical direction; in fact for SERN 


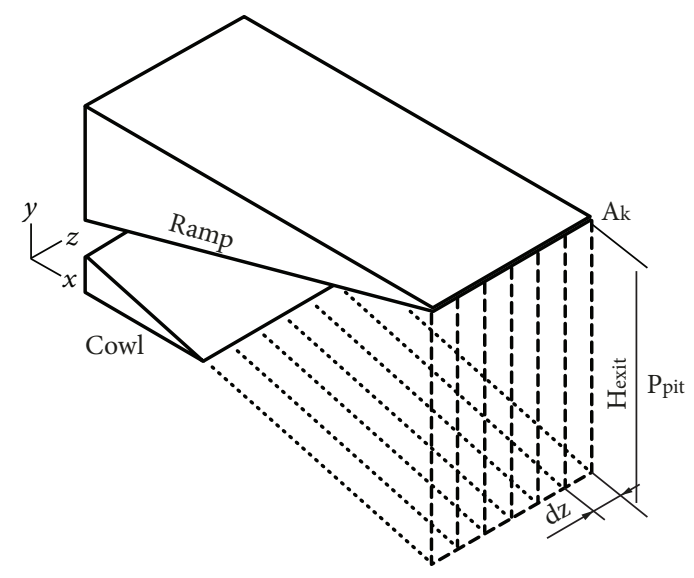

Figure 8: Sketch of the area division at the nozzle exit.

nozzles, there is an expansion of the flow in the vertical direction $(y)$ [16]; however, it was not measured during the experiments. This methodology allows to obtain an approximation of the effects caused by the side walls in the thrust of the central region of the nozzle.

Due to instrumental restrictions in the experimental setup, the static pressure data could only be obtained at two positions of the expansion ramp. Therefore, the area of influence of the measurements does not cover the whole ramp surface. The pressure data are available at two points along the centerline of the surface as shown in Figure 9. The ramp surface was divided by the number of available sensors, and the measured pressure is considered constant over the area of influence. For analysis simplification, the pressure values measured by the pressure transducers along the centerline of the ramp are considered on the centerline of the cowl surface and on the exhaust plume. This simplification allows to obtain the thrust at the central line of the nozzle surface as a function of the pressure distribution in the $x$ direction but does not consider the effects of the side walls installed in the nozzle.

Equation (5) is used to calculate the forces from the pressure data obtained by static pressure transducers:

$$
\begin{aligned}
F_{x} & =\left(p_{k}-p_{e}\right) * \Delta l_{k} * \sin \alpha_{k} \\
F_{y} & =\left(p_{k}-p_{e}\right) * \Delta l_{k} * \cos \alpha_{k} \\
\alpha_{k} & =\arctan \left(\frac{\mathrm{dy}_{k}}{\mathrm{dx}_{k}}\right) \\
\Delta l_{k} & =\sqrt{\mathrm{dx}_{k}^{2}+\mathrm{dy}_{k}^{2}}
\end{aligned}
$$

where $\alpha$ is the angle of the pressure magnitude, $\Delta l$ is the length of the area of influence on the nozzle surface, and index $k$ is the reference to the static pressure transducer. The total force $F$ consists of three components: the momentum part, the contribution of the force obtained from static pressure transducers on the ramp, and the contribution of the force from the exhaust plume downstream of the cowl. The thrust of the ramp is calculated by multiplying the thrust of each transducer with the

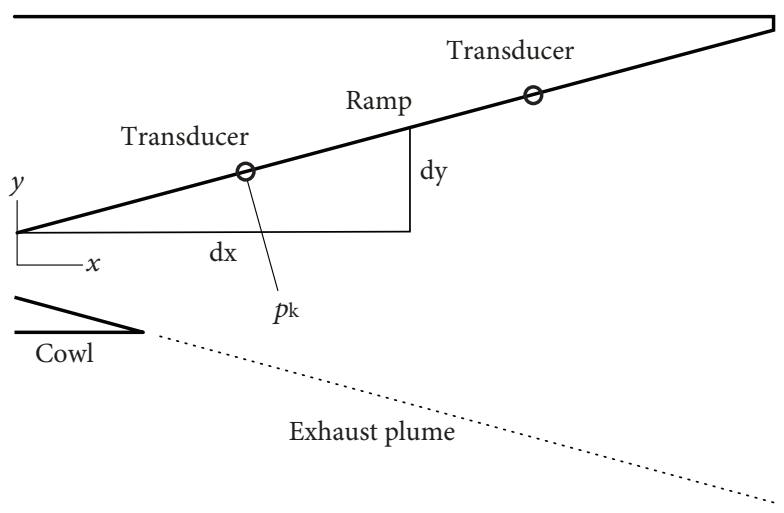

FIGURE 9: Sketch of the area of influence for static pressure transducers.

corresponding width of the area of influence, that is, the span nozzle. These values are mirrored about the cowl and the exhaust plume surface because pressure measurements of this region are unavailable. The contribution of the momentum at the entrance of the nozzle is also included according to

$$
F=\rho V^{2} A_{\text {in }}+2 \sum F_{k}
$$

\section{Results}

Experiments were performed with printed side walls (see Figure 10(a)) and without side walls (see Figure 10(b)). The pressure distribution at the nozzle exit is measured by the pitot rake, while the static pressure on the nozzle centerline is measured by pressure transducers. Flow expansion from the exit combustor conditions to the nozzle exit is assumed to be isentropic.

The nozzle inflow conditions are summarized in Table 3. The static pressure at the nozzle entrance is obtained from experimental pressure measurements, and the Mach number is determined from one-dimensional theoretical model.

Figure 11 illustrates the static pressure distribution considering the side walls (cases 1-4) measured across the nozzle exit span. The pressure is nondimensionalized using the higher pressure measurement from case 1 to case 4. Also, the pressure measurements are similar considering the nozzle locations. Furthermore, it can be seen that the pressure profile of the nozzle is not symmetrically relative to the center line of the span. A pressure reduction in both directions from the nozzle centerline is observed. Assuming the nozzle center as reference, the pressure distribution in the positive direction of the span $\left(z^{+}\right)$is greater in comparison with the pressure distribution in the negative direction of the $\operatorname{span}\left(z^{-}\right)$. The pressure distribution of the SERN nozzle is symmetric in the width direction [29]; for the results obtained in Figure 11, the difference of the pressure distribution with respect to the central line can be attributed to interferences in the compression section geometry or in the combustion chamber geometry of the experimental model.

Figure 12 illustrates the static pressure distributions for the nozzle without side walls (cases 5-7) measured across 


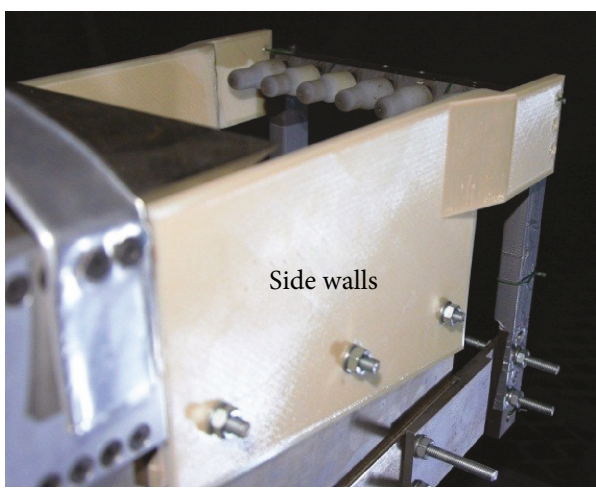

(a)

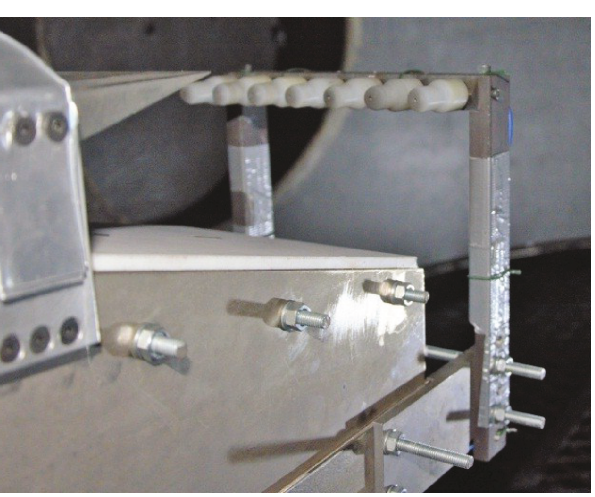

(b)

Figure 10: Nozzle and pitot rake in the hypersonic shock tunnel: (a) with side wall configuration and (b) without side wall configuration.

TABLe 3: Nozzle inlet conditions.

\begin{tabular}{lccc}
\hline Case & $p_{\text {in }}[\mathrm{kPa}]$ & $M_{\text {in }}$ & Nozzle side walls \\
\hline 1 & $14.7 \pm 0.6$ & $3.3 \pm 0.2$ & Yes \\
2 & $16.0 \pm 0.8$ & $3.2 \pm 0.2$ & Yes \\
3 & $14.3 \pm 0.6$ & $3.2 \pm 0.2$ & Yes \\
4 & $16.0 \pm 0.7$ & $3.2 \pm 0.2$ & Yes \\
5 & $19.7 \pm 0.8$ & $3.1 \pm 0.2$ & None \\
6 & $20.2 \pm 0.5$ & $3.1 \pm 0.2$ & None \\
7 & $21.2 \pm 0.6$ & $3.1 \pm 0.2$ & None \\
\hline
\end{tabular}

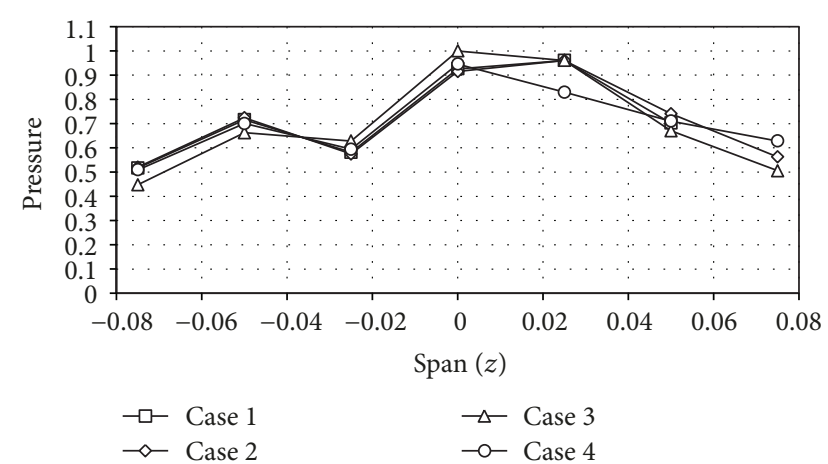

FIGURE 11: Normalized pressure measurements at the nozzle exit with side walls.

the nozzle exit span. The pressure is nondimensionalized using the larger pressure measurement from case 5 to case 7 . Similarly, to the cases with side walls, the flow at the nozzle exit is not symmetric. Moreover, a slight difference of the pressure distributions in the spanwise direction can be observed, specifically by the measurement of the sensor at $x=-0.25$. Comparing the measurement patterns of both configurations, the measurements of this sensor are repetitive. This behavior can be caused by the flow conditions inside the combustion chamber; therefore, the field of pressures inside the combustion chamber was analyzed.

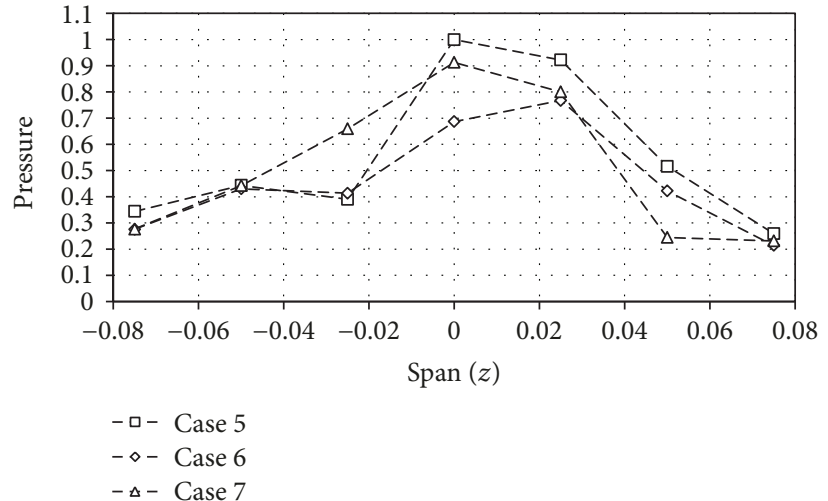

FIGURE 12: Normalized pressure measurements at the nozzle exit without side walls.

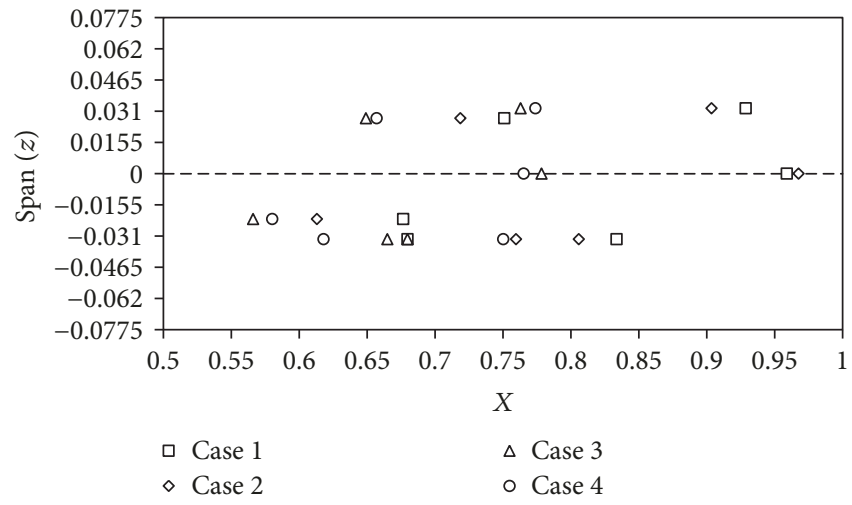

FIGURE 13: Normalized pressure inside the combustor.

Figure 13 shows the normalized pressure results inside the combustor. The results were normalized by each sensor position. The measurements were obtained by static pressure transducers installed in the span direction and length of the combustion chamber. It can be observed that in the lower part of the combustor $\left(z^{-}\right.$direction), the normalized values of the pressure (horizontal axis) are lower 


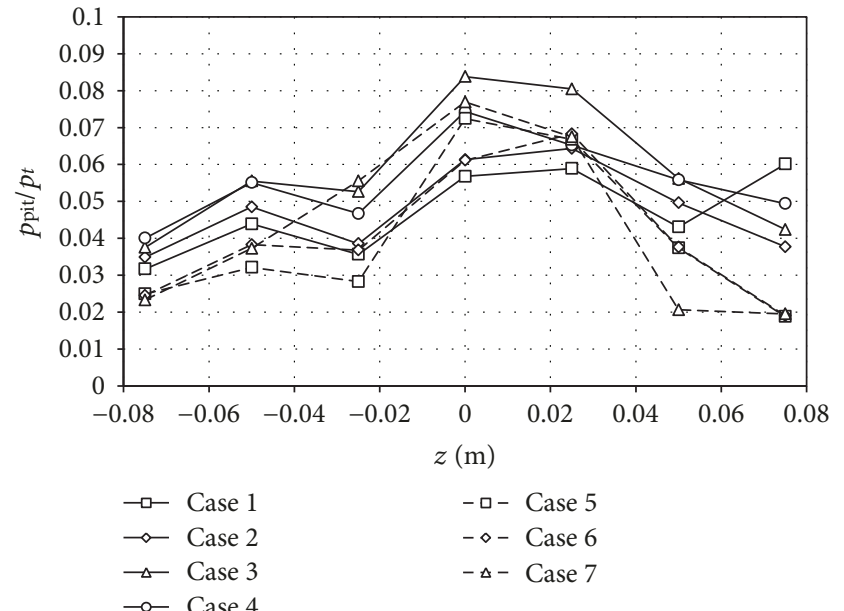

Figure 14: Comparison of normalized pitot measurements at the nozzle exit with side wall (solid lines) and without side wall (dashed lines) configurations.

than those of the correspondent upper part. This indicates that the pressure distribution at span direction inside the combustion chamber is nonsymmetrical. This difference is also observed in the pressure distribution of the measurements of the rake (Figures 11 and 12).

The pitot pressure measurement for both configurations was normalized by the combustor exit total pressure for comparison. Figure 14 shows the normalized values for side wall (solid lines) and without side wall (dashed lines) configurations.

It could be expected that the pressure distribution would be smaller for the configuration without side walls (dashed line). However, comparing the results of pressure measurements from the center region of the nozzle can be seen that they are very similar for both configurations. It can be attributed to very short residence time of the flow in the nozzle due to the high flow velocity and the dimensions of the nozzle. Therefore, the air mass of the central region is not altered by lateral expansion.

Furthermore, the result comparison shows that a pressure drop extends from the centerline toward the sides of the nozzle for both configurations. The pressure drop is higher for cases without side walls. This pressure drop is caused by the lateral expansion when the flow is not confined by the side walls. The air mass flow is spilling through the sides of the nozzle; hence, the pressure in the sides of the nozzle is lower than in the cases with side walls.

Figure 14 also shows that the pressure distribution maintains the same pattern for all cases; this behavior is determined by the nonsymmetrical flow in the combustor as discussed above.

Figure 15 shows the static pressure measurement on the centerline for nozzle configuration with side walls and without side walls. Comparing the results, it can be seen that the pressure profiles are very similar for both configurations. This behavior consolidates the hypothesis that the residence time of the flow in the expansion section is short enough to the flow of the central region of the nozzle which is not
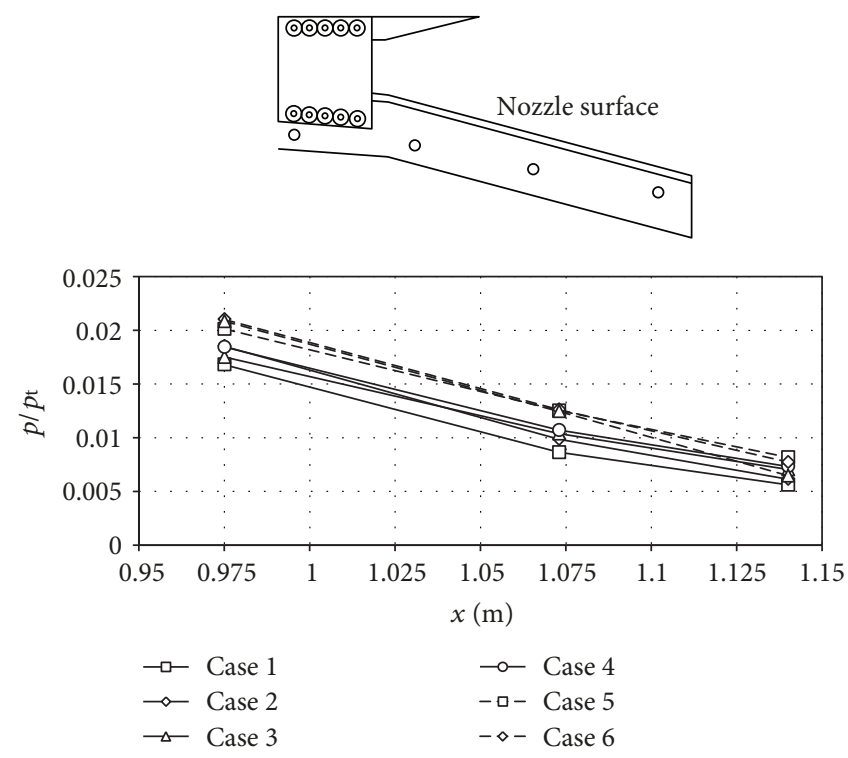

FIgURE 15: Comparison of normalized static pressure measurement at the nozzle surface with side wall (solid lines) and without side wall (dashed lines) configurations.

TABle 4: Pitot thrust measurement.

\begin{tabular}{|c|c|c|}
\hline Sensor & $F[N]$ with side wall & $\mathrm{F}[N]$ without side wall \\
\hline Pitot 1 & $71 \pm 8$ & $54 \pm 7$ \\
\hline Pitot 2 & $200 \pm 11$ & $159 \pm 5$ \\
\hline Pitot 3 & $170 \pm 7$ & $177 \pm 8$ \\
\hline Pitot 4 & $270 \pm 8$ & $315 \pm 10$ \\
\hline Pitot 5 & $265 \pm 9$ & $302 \pm 8$ \\
\hline Pitot 6 & $202 \pm 7$ & $143 \pm 10$ \\
\hline Pitot 7 & $96 \pm 12$ & $42 \pm 5$ \\
\hline Total & $1303 \pm 90$ & $1196 \pm 52$ \\
\hline
\end{tabular}

altered by the lateral expansion when nozzle configuration does not include side walls.

4.1. Measurement Generated Thrust. The thrust that is generated by the SERN nozzle is calculated by two different ways in the present work. The thrust is calculated from the measured pressure of the rake and also from the static pressure transducers. The results obtained by the pitot thrust calculations from both configurations are compared to highlight the differences.

A comparison of nozzle thrust between configurations with and without side walls is listed in Table 4; the thrust computed from each pitot pressure sensor and the total thrust nozzle are compared.

The nozzle total axial thrust with the side wall is slightly higher than without side wall configuration. The difference lies between 4 and $54 \%$ for the sensors of the central region of the nozzle and for the lateral region of the nozzle, respectively. The reason for this difference is that pressure losses in the lateral region of the nozzle produce lower thrust as shown by the values of the pitot 1 and pitot 7 sensors. 
TABle 5: Nozzle performance comparison.

\begin{tabular}{lccc}
\hline Case & $\mathrm{F}[N]$ & $C_{f}$ & Lift $[N]$ \\
\hline With side wall & $2273 \pm 75$ & 0.517 & $210 \pm 11$ \\
Without side wall & $2167 \pm 87$ & 0.502 & $188 \pm 14$ \\
\hline
\end{tabular}

Nozzle thrust, axial thrust coefficient, and lift obtained through static pressure measurement are listed in Table 5. For this methodology, the momentum component at the entrance of the nozzle supplies the major contribution to the thrust. The differences between results are due to the difference in pressure on the nozzle sides by installation of side walls. The results of the axial thrust coefficient show that the SERN with side walls produces a $5 \%$ greater axial thrust than the nozzle without side walls.

\section{Conclusions}

Experimental investigation was carried out with a single expansion ramp nozzle at the hypersonic shock tunnel. The nozzle inlet conditions are provided directly by the combustor exit section. Side walls were installed on the scramjet nozzle to study its effects on thrust, thrust coefficient, and lift for the nozzle. The measurements obtained by pitot probes across of the nozzle exit span show that the flow at the nozzle exit is not symmetric. The pressure distribution at the nozzle exit shows that there is a pressure drop in the direction of the laterals of the nozzle. This pressure drop is greater for the configuration without side walls due to lateral expansion of the flow (spillage). Static pressure measurements inside the combustion chamber show nonuniform flow condition which is carried on until the end of the expansion for both nozzle configurations. Measurements of static pressure on the nozzle surface show that the nozzle central region is not affected by lateral expansion without side walls. Pitot pressure and static pressure measurements were used to determine nozzle performance parameters. The results of the axial thrust coefficient show that the SERN with side walls produces a $5 \%$ greater axial thrust than the nozzle without side walls.

\section{Data Availability}

The experimental data used to support the findings of this study have not been made available because some information is part of a protected program.

\section{Conflicts of Interest}

The authors declare that there is no conflict of interest regarding the publication of this paper.

\section{Acknowledgments}

This study was financed in part by the Coordenação de Aperfeiçoamento de Pessoal de Nível Superior (CAPES), Brazil (finance code 001). The first author would like to thank the Graduate Program in Space Sciences and Technologies of the Instituto Tecnológico de Aeronáutica (ITA/Brazil) and the CAPES for the financial support to doctoral studies. This work has been partially sponsored by the European Space Research and Technology Centre (ESTEC), and the second author would like to extend his appreciation to this sponsor for supporting the project. A portion of this study was supported by the Instituto de Estudos Avançados (IEAv) and by the Propulsão Hipersônica 14-X (PropHiper) Project, and the third author would like to express his appreciation to these sponsors. Finally, the last two authors (as visiting professors) would like to express their appreciation to the Universidade Federal do Rio Grande do Norte (UFRN) for the support given to complete this scientific work and also for the possibility to apply the knowledge in aerothermodynamics and hypersonics in the research area in hypersonic airbreathing propulsion based on supersonic combustion ramjet (scramjet) technology.

\section{References}

[1] P. G. P. Toro, M. A. Minucci, T. Rolim et al., "Brazilian 14-X hypersonic aerospace vehicle project," in 18th AIAA/3AF International Space Planes and Hypersonic Systems and Technologies Conference, pp. 1-11, Tours, France, 2012.

[2] J. F. de Araújo Martos, Investigação Experimental do Veículo Hipersônico Aeroespacial 14-X B, [M.S. thesis], Engenharia Mecanica, Universidad Federal do ABC, Santo André, Brazil, 2014.

[3] J. F. de Araujo Martos, I. da Silveira Rêgo, S. N. Pachon Laiton, B. C. Lima, F. J. Costa, and P. G. de Paula Toro, "Experimental investigation of Brazilian 14-X B hypersonic scramjet aerospace vehicle," International Journal of Aerospace Engineering, vol. 2017, Article ID 5496527, 10 pages, 2017.

[4] I. F. R. Barón, Experimental Investigation of the Scramjet Demonstrator 14-X B with Mach Number of 6 to 12 in the Hypersonic Shock Tunnel, [M.S. Thesis], Program of Space Science and Technology, Area of Space Propulsion and Hypersonics, Instituto Tecnológico de Aeronáutica, Sao José dos Campos, Brazil, 2014.

[5] R. A. Oman, K. M. Foreman, J. Leng, and H. B. Hopkins, "Simulation of hypersonic scramjet exhaust," Tech. Rep. NASA CR-2494, Berthpage, NY, USA, 1975.

[6] P. L. Moses, V. L. Rausch, L. T. Nguyen, and J. R. Hill, "NASA hypersonic flight demonstrators-overview, status, and future plans," Acta Astronautica, vol. 55, no. 3-9, pp. 619-630, 2004.

[7] H. Herrmann and H. Rick, "Propulsion aspects of hypersonic turbo-ramjet-engines with special emphasis on nozzle/aftbody integration," in ASME 1991 International Gas Turbine and Aeroengine Congress and Exposition, pp. 1-9, Orlando, FL, USA, 1991.

[8] T. Cain, "Scramjet nozzles," Tech. Rep. EN-AVT-185-12 RTO, Hampshire, UK, 2010.

[9] W. Huang, Z. G. Wang, S. B. Luo, and J. Liu, "An overview of research on engine/airframe integration for hypersonic waverider vehicles," Guti Huojian Jishu/Journal of Solid Rocket Technology, vol. 32, pp. 242-248, 2009.

[10] J. Mo, J. Xu, Z. Quan, K. Yu, and Z. Lv, "Design and cold flow test of a scramjet nozzle with non-uniform inflow," Acta Astronautica, vol. 108, pp. 92-105, 2015. 
[11] T. Edwards, "The effect of exhaust plume/afterbody interaction on installed scramjet performance," in 27th Aerospace Sciences Meeting, pp. 1-105, Reno, NV, USA, 1989.

[12] W. C. Engelund, S. D. Holland, C. E. Cockrell, and R. D. Bittner, "Aerodynamic database development for the hyper-X airframe-integrated scramjet propulsion experiments," Journal of Spacecraft and Rockets, vol. 38, no. 6, pp. 803-810, 2001.

[13] E. T. Curran and S. N. B. Murthy, Eds., Scramjet Propulsion, vol. 189 of Progress in Astronautics and Aeronautics, American Institute of Aeronautics and Astronautics, Reston, VA, USA, 2001.

[14] F. W. Spaid and E. R. Keener, "Experimental results for a hypersonic nozzle/afterbody flow field," in 28th Joint Propulsion Conference and Exhibit, pp. 1-21, Nashville, TN, USA, 1992, AIAA-92-3915.

[15] V. Thiagarajan, S. Panneerselvam, and E. Rathakrishnan, "Numerical flow visualization of a single expansion ramp nozzle with hypersonic external flow," Journal of Visualization, vol. 9, no. 1, pp. 91-99, 2006.

[16] S. Watanabe, "Scramjet nozzle experiment with hypersonic external flow," Journal of Propulsion and Power, vol. 9, no. 4, pp. 521-528, 1993.

[17] W. J. Monta, "Pitot survey of exhaust flow field of a 2-D scramjet nozzle at Mach 6 with air or Freon and argon used for exhaust simulation," Tech. Rep. NASA TM-4361, Hampton, VA, USA, 1992.

[18] Z. Lv, J. Xu, Y. Yu, and J. Mo, "A new design method of single expansion ramp nozzles under geometric constraints for scramjets," Aerospace Science and Technology, vol. 66, pp. 129-139, 2017.

[19] W. Huang, Z. G. Wang, D. B. Ingham, L. Ma, and M. Pourkashanian, "Design exploration for a single expansion ramp nozzle (SERN) using data mining," Acta Astronautica, vol. 83, pp. 10-17, 2013.

[20] L. Jianping, S. Wenyan, X. Ying, and L. Feiteng, "Influences of geometric parameters upon nozzle performances in scramjets," Chinese Journal of Aeronautics, vol. 21, no. 6, pp. 506511, 2008.

[21] C. M. Hirschen, A. Gülhan, W. Beck, and U. Henne, "Measurement of flow properties and thrust on scramjet nozzle using pressure-sensitive paint," Journal of Propulsion and Power, vol. 25, no. 2, pp. 267-280, 2009.

[22] C. Hirschen, A. Gülhan, W. Beck, and U. Henne, "Experimental study of a scramjet nozzle flow using the pressure-sensitive-paint method," Journal of Propulsion and Power, vol. 24, no. 4, pp. 662-672, 2008.

[23] R. Hiers and D. Pruitt, "Determination of thrust from pitot pressure measurements," in 37th Joint Propulsion Conference and Exhibit, pp. 1-5, Salt Lake City, UT, USA, 2001, AIAA 2001-3314.

[24] R. Lederer and W. Krüeger, "Nozzle development as a key element for hypersonics," in 5th International Aerospace Planes and Hypersonics Technologies Conference, pp. 1-6, Munich, Germany, 1993, AIAA-93-5058.

[25] T. Shimura, N. Sakuranaka, T. Sunami, and K. Tani, "Thrust, lift, and pitching moment of a scramjet engine," Journal of Propulsion and Power, vol. 17, no. 3, pp. 617-621, 2001.

[26] P. G. P. Toro, M. A. S. Minucci, J. B. Chanes, A. L. Pereira, and H. T. Nagamatsu, "Development of a new hypersonic shock tunnel facility to investigate electromagnetic energy addition for flow control and basic supersonic combustion," in 4th International Symposium on Beamed Energy Propulsion, vol. 830 of AIP Conference Proceedings, pp. 469-480, Nara, Japan, 2006.

[27] S. N. P. Laitón, Estudo Teórico-Analítico do Veículo Hipersônico Aeroespacial 14-X B em Ângulo de Ataque, [M.S. thesis], Área de Propulsão Espacial e Hipersônica-Ciências e Tecnologias Espaciais, Instituto Tecnológico de Aeronáutica, São José dos Campos, Brazil, 2015.

[28] A. F. Moura, A Computational Study of the Airflow at the Intake Region of Scramjet Engines, [M.S. Thesis], Program of Space Science and Technology, Area of Space Propulsion and Hypersonics, Instituto Tecnológico de Aeronáutica, Sao José dos Campos, Brazil, 2014.

[29] E. R. Keener and F. W. Spaid, "Hypersonic nozzle-afterbody experiment - flow visualization and boundary-layer measurements," Journal of Spacecraft and Rockets, vol. 33, no. 3, pp. 326-332, 1996. 


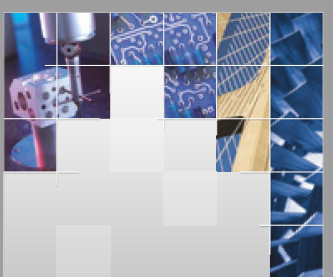

\section{Enfincering}
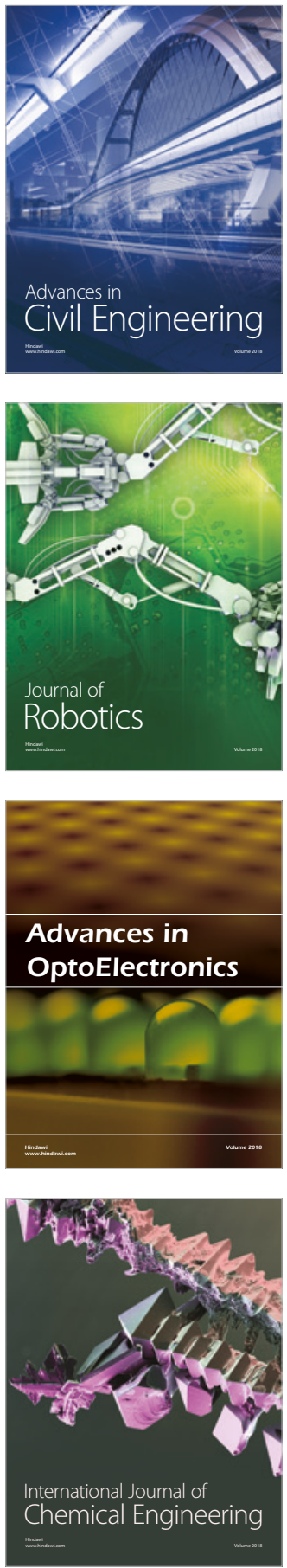

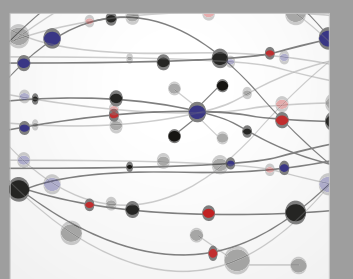

\section{Rotating \\ Machinery}

The Scientific World Journal

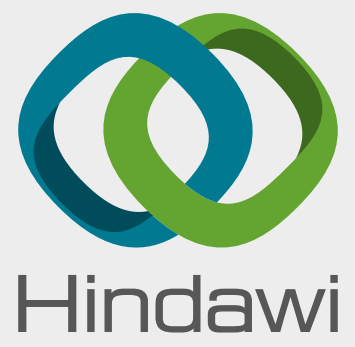

Submit your manuscripts at

www.hindawi.com
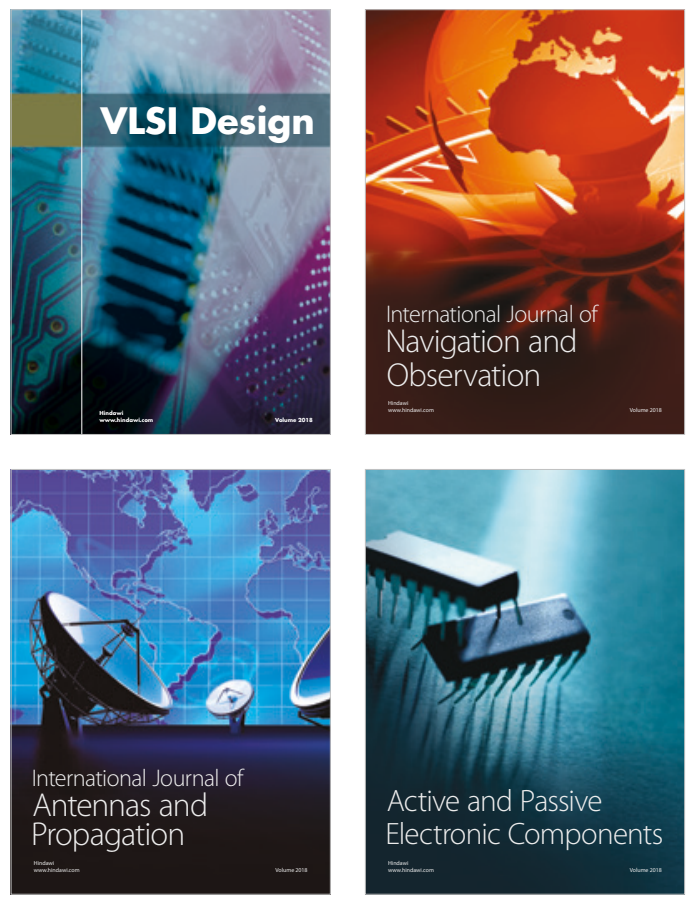
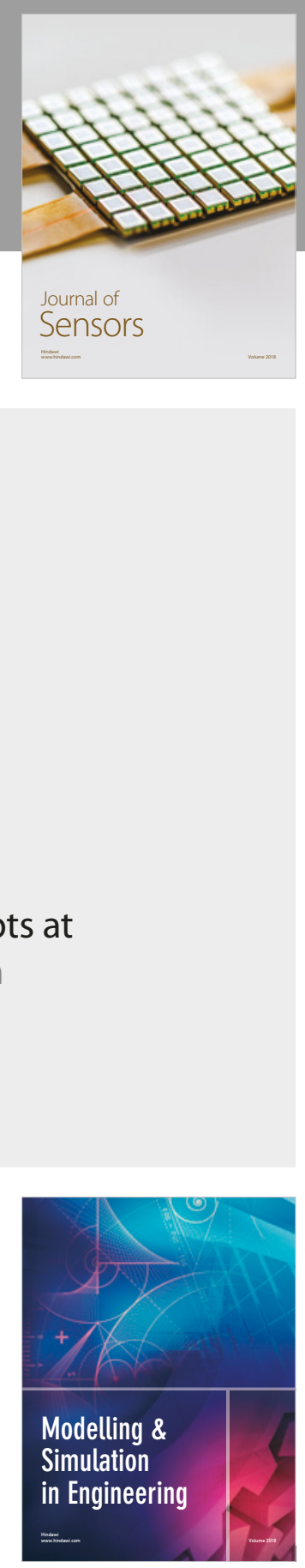

\section{Advances \\ Multimedia}
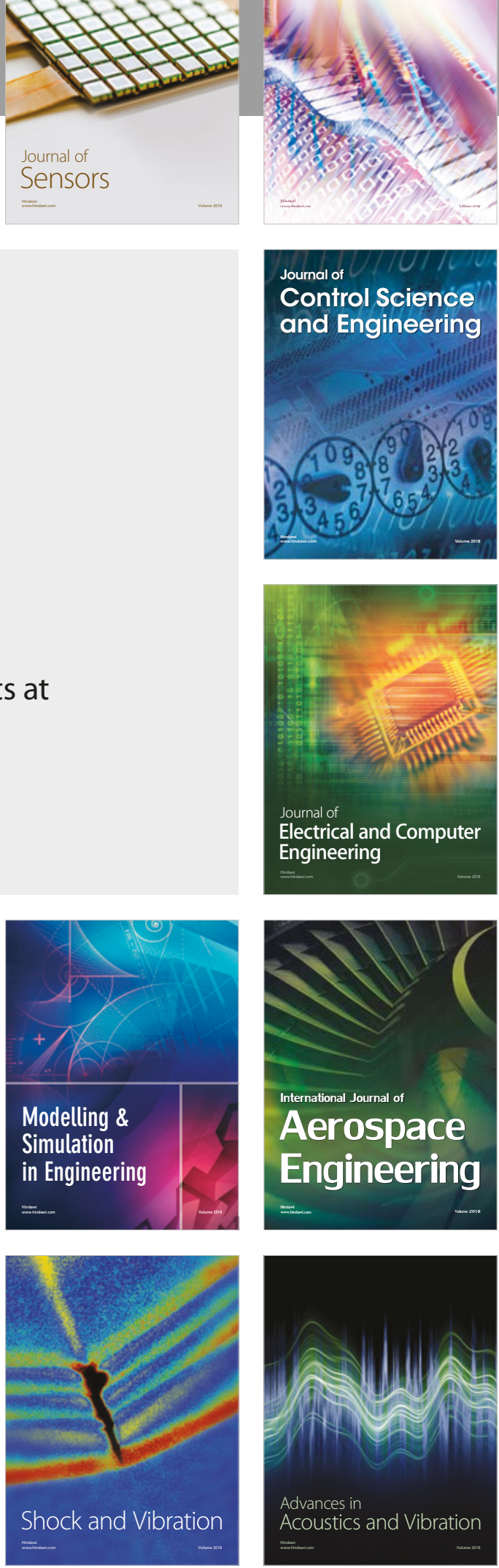